\title{
THE RELATIONSHIP \\ BETWEEN WORKPLACE \\ PRACTICES AND FIRM LEVEL \\ PRODUCTIVITY IN NEW \\ ZEALAND
}

Grant Andrews and Brett Lineham

Department of Labour

\begin{abstract}
Raising New Zealand's growth in productivity (ie output per person employed or hour worked) has become a topic of increasing political and academic debate. This has been driven by recognition that the relative decline in our incomes (compared to those of other developed nations) is a direct consequence of our inability to raise our productivity at a comparable rate.
\end{abstract}

In this paper, we examine issues relating to achievement of productivity growth within organisations. We firstly contextualise this by providing a general overview of productivity trends, including the connection between firm-level and wider productivity. We then outline a framework for considering business practices and how these might affect workplace productivity; review New Zealand research findings about the relationship between workplace practices and firm-level productivity growth; and discuss the results of recent studies (done or funded by the Department of Labour) of change processes within organisations.

From this, we conclude that there is a wide range of business improvement options, depending on the needs of the individual organisation; that significant improvements in workplace practices can be achieved; and that these contribute to a range of better operational outcomes. Ultimate benefits in productivity can be expected but are harder to attribute. However, the experience of the organisations studied highlights the challenges inherent in these processes, which require sustained commitment, and buy-in from people at all levels. There were significant differences in outcomes between those organisations that began with positive internal relationships and culture, and management leadership, and those where these conditions were absent.

\section{Introduction}

Since 2004, the Department of Labour has funded activities under the Workplace Productivity Agenda (WPA), including awareness raising, tool development and communications; and consultancy support to provide selected firms with practical, hands-on assistance in implementing productivity-enhancing processes within the workplace.

The genesis of this paper was a strategic review of the programme, covering both evaluations of the above activities, and a review of the relevant literature. While the objective of our work was policy development, we considered that our findings might have general interest to researchers in this area.

The focus of this paper is on the mechanisms for productivity improvement within organisations. As a corollary, we do not examine external influences on productivity growth within firms - product and factor markets, regulation etc. These are clearly very important, but our interest is in what firms do to lift their productivity within the given environment.

We gratefully acknowledge our colleagues who provided input to this paper and other work that informed it, and the Department of Labour for supporting our presentation of this paper.

\section{Overall productivity trends}

Labour productivity is measured as real (inflation adjusted) Gross Domestic Product per paid hour of all persons employed in production of goods and services (SNZ 2010). Growth in labour productivity is the primary source of income growth; hence the fact that New Zealand's labour productivity has been growing more slowly than in most other developed nations is the key reason for the decline in our relative incomes (OECD 2009). 
Figure 1: Productivity trends in New Zealand 1978-2009

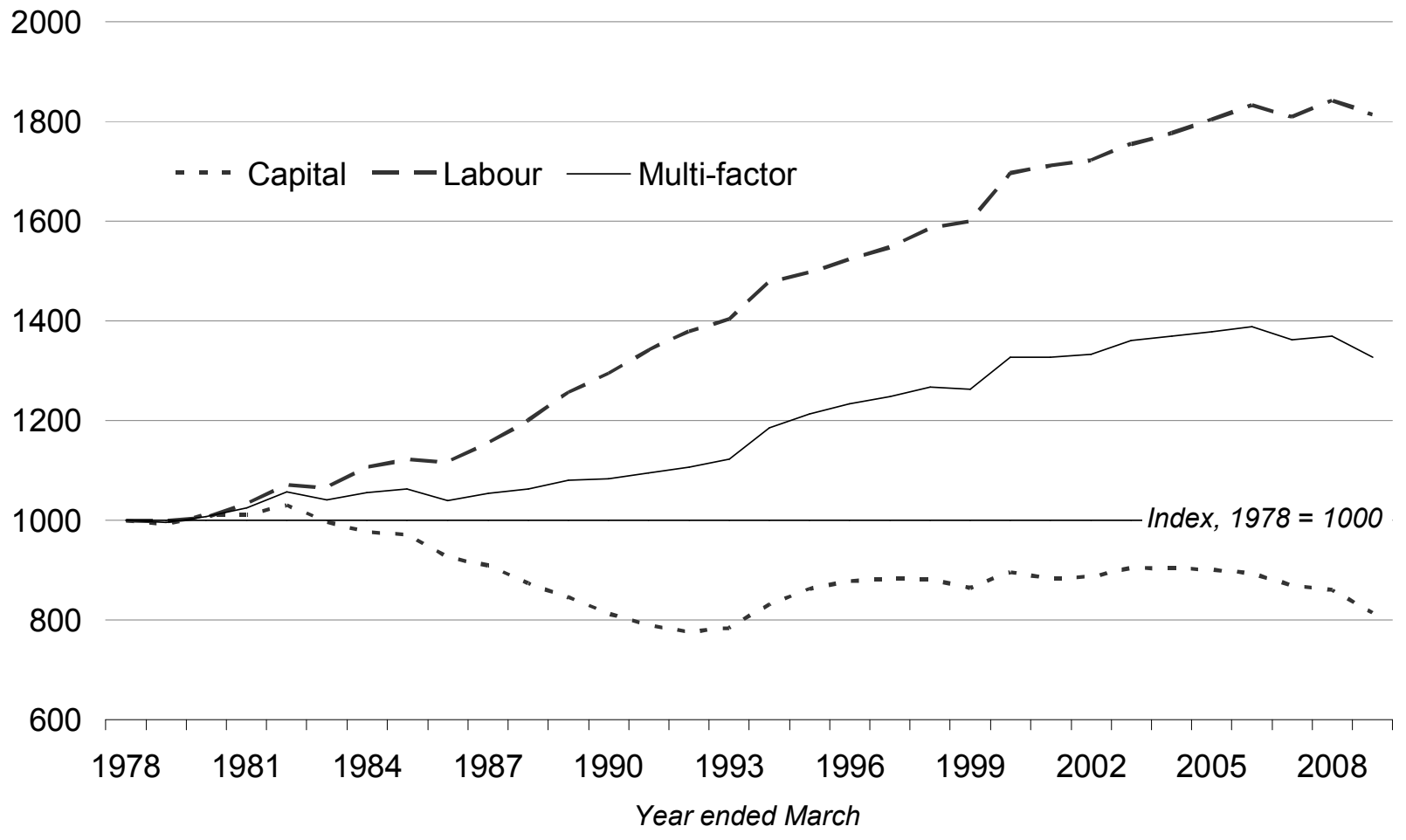

Source: Statistics New Zealand Infoshare Productivity Indexes (Annual-Mar)

The long-term story about New Zealand's productivity is illustrated in Figure 1 above:

- labour productivity grew by $1.9 \%$ per annum between the March 1978 and 2009 years

- capital productivity fell by an average of $0.7 \%$ per annum over the thirty-one year period, as the stock of capital assets (to be precise, the services provided by the capital stock) apparently expanded more rapidly than output.

- Multi-Factor Productivity (MFP - the growth in output not explained by increase in inputs of capital and labour) grew by $0.9 \%$ per annum over the thirty-one years.

A particular feature of the current decade was that the strong economic growth of the early period was job-rich. This was positive in so far as it resulted in high labour force participation and very low unemployment rates (until 2007); but the downside of this and the subsequent slowdown is low labour productivity growth, of $0.8 \%$ per annum in the nine years since the March 2000 year (and MFP unchanged).

Moving from the macro to the meso, we examined papers relating to industry-level productivity that influenced our thinking.
Firstly, Treasury (2005) and Fabling et al (2008) analysed within-industry productivity, growth in New Zealand, from the mid/late 1990s to the middle of the current decade. They replicated the methodology in OECD (2004), and found similar results; that the main source of productivity growth within industries was rising productivity among incumbent firms (those which had been continuously in operation over the period).

A material but smaller lift came from new firms (as in the US), but, unlike Europe, relatively little from exit of firms with below-average and declining productivity.

Secondly, Fabling and Grimes (2006) examined the relative importance of environmental and internal "resource-based" factors, ie between the factors that firms can and cannot control.

After controlling for firm size, age and industry - in effect grouping firms according to common characteristics and external factors - they found considerable heterogeneity in measures of business success within groups of apparently similar firms.

In other words, differences in firm performance appear to be explained in large measure by how firms managed themselves within a given environment - ie by factors over which they had some control - rather than purely by exogenous factors. 
The significance of these findings to our thinking is that they suggest that most productivity improvement comes as a result of existing firms 'lifting their game', and that they have considerable scope to do so.

This then takes us to thinking about the micro - the productivity story within firms.

\section{Workplace practices - a framework}

\section{Taxonomies of workplace/ business practices}

In this section we examine the linkages between workplace practices and productivity. By workplace practices, we mean the range of procedures, routines, methods, etc that are used by individual firms (sometimes referred to as business practices).

We have drawn heavily on 'Firm Foundations' (MED 2002) which provides a framework that draws on a range of management literature and attempts to bring together markets, strategy, business practices and business outcomes. It lists business practices in the following categories:

- $\quad$ leadership and planning

- customer focus

- employee relations

- $\quad$ quality and supplier focus

- innovation and technology
- information and benchmarking.

The Firm Foundations taxonomy has been largely replicated in the Statistics New Zealand Business Operations Survey (BOS) (SNZ undated). See SNZ (2009) for a sample of the most recent questionnaire.

There are a variety of methods used in the BOS for measuring business practices. With regard to employment practices, most questions take the form of "what percent of employees are subject to particular practices (eg performance reviews, training)?"

Other "soft" factors such as culture, management style, internal communications, and intra-firm relationships are also important. We can think of these as the conditions within firms that affect the application of business practices.

However, testing the importance of these factors is highly problematic, as they are not as easily measureable as specific actions that constitute business practices. We discuss these influences in later sections,

\section{How do practices affect productivity?}

There is a seemingly obvious proposition, that firms which do better in some or all of these business practices should achieve, and be able to demonstrate, better business outcomes.

The MED (ibid) model is shown below.

Figure 2: The Firm, Business Practices, Distinctive Capabilities, and Competitive Advantage 
The key elements of the model are

- $\quad$ structural issues (size, ownership, sector, age of business)

- $\quad$ strategy (competitive priorities and exporting status)

- $\quad$ practices [per above]

- innovation and technology, and information and benchmarking

- outcomes on competitiveness, quality and service timeliness, flexibility, innovation and human resource measures

- $\quad$ business results such as, productivity, profitability and sales

The central premise of the model is that business excellence is holistic in that all elements of the model must be in place and consistently linked together for a business to achieve sustainable outcomes.

Our framework is simpler, focussing on the sequence of causality from

- business/workplace practices (what firms do on a day-to-day basis)

to

- operational outcomes (how efficiently they function)

to

- business outcomes (what they achieve in terms of profits, productivity)

We would expect the connection between improved business/workplace practices and operational outcomes (eg less downtime, less waste etc) to be relatively transparent and subject to short time lags. However, the connection between operational and business outcomes is likely to be more oblique, being subject to longer time lags (1-2 years and longer) and external influences (eg changes in external markets) (MED op.cit).

Hence while improved business/workplace practices should ultimately result in better productivity and profitability, this linkage is less clear cut.

When we examine how this framework is applied in practice, we note that

- empirical research has not examined the connections as a two-step process, but has generally moved from practices directly to business outcomes

- evaluations and case studies have focussed on the connection between practices and operational outcomes, and have been unable to fully examine the step to business outcomes.

This is illustrated below:

Figure 3: Business practices and outcomes

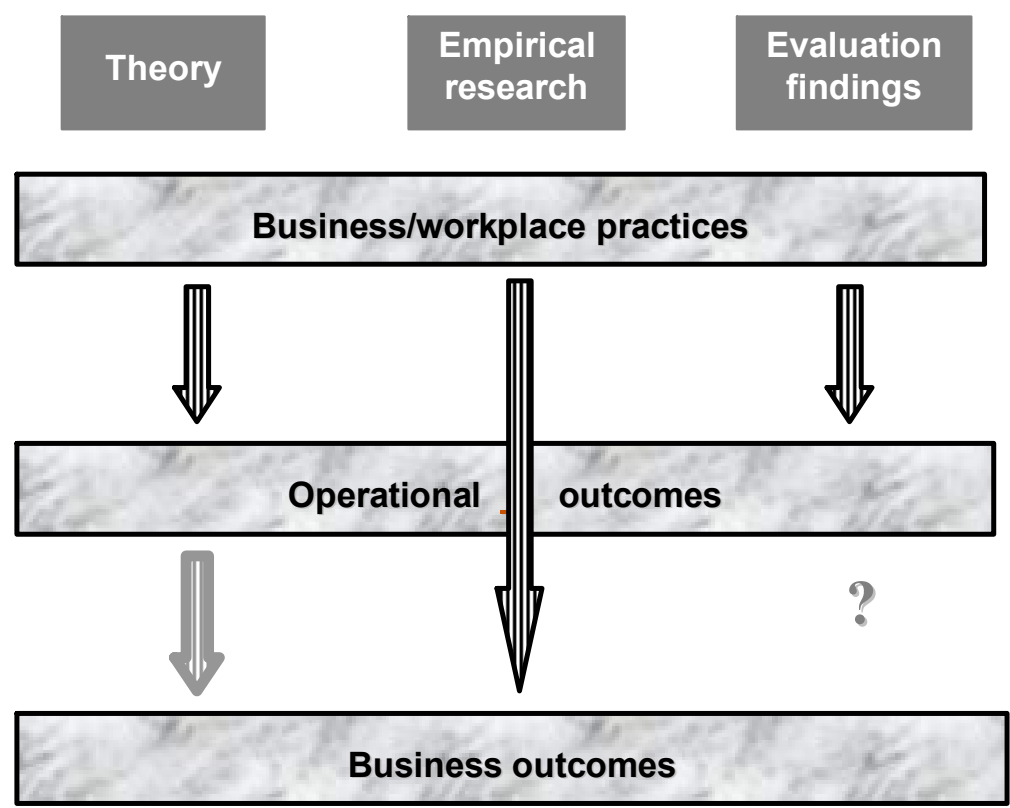




\section{Empirical research}

Most New Zealand empirical evidence about the productivity impacts of improved business and employment practices derives from MED (op.cit) (with 2001 data), and subsequent work by Fabling and Grimes. The latter have taken the 'Firm Foundations' analysis further by applying more sophisticated econometric tools, and in later studies, by augmenting the original data set.

The key conclusions of MED (op.cit) were that:

- certain business practices appeared to yield advantages to firms when used in combination.

- there is no single model to apply, nor can better business results be achieved through a one-step process; rather, the authors emphasised the importance of business improvement as a continuous process.

- there appeared to be a relationship between adopting improved business practices in an "holistic" manner, and better operational outcomes.

With respect to employment practices, "the study points to mixed efforts", with

- a lack of systematic, long-term performance management; almost $40 \%$ of firms did not undertake performance reviews, and over $50 \%$ lacked formal linkages between performance and remuneration.

- widespread provision of internal staff training ( $85 \%$ of surveyed firms); with a query as to how effective this is likely to be, given the absence of performance management to identify business and employee development needs

- $\quad$ significant albeit lower use of external training (70\% of firms), but for a smaller pool of employees $(25 \%)$

- "demonstrating a commitment to the welfare of staff", through activities such as regular assessments of employee satisfaction $(85 \%$ of firms), implementation of health and safety processes ( $85 \%$ of firms), and "initiatives to foster a culture of teamwork and communication".

Fabling and Grimes (2006) examined which business practices set successful firms apart from others, using the 'Firm Foundations' dataset. 'Business success' was measured in terms of relative profitability, relative productivity and market share.

They examined the relationship between various types of business practice, and between these and business outcomes, and concluded that four categories of business practices were particularly important contributors to business success:

- investment in up-to-date capital equipment capital-augmenting

- labour-augmenting (and/or efficiencyenhancing) employee-related practices

- $\quad \mathrm{R} \& \mathrm{D}$

- market research (associated with only one success measure, higher market share)

With regard to employment practices, they highlighted incentive practices (adoption of performance pay for most employees) and more general HR practices (eg measuring employee satisfaction), and concluded that

The finding that a range of employee (human resource) practices is significant (i.e. measuring employee satisfaction, job rotation, delegating authority to employees, adopting performance pay and investing in training), is consistent with [earlier] findings that a package of human resource practices is important for firm performance.

A common theme from these and other studies is that better practices in one area have limited impact; it is the ability of firms to lift their game across the board that leads to better business performance.

The connection between employment practices and business performance was examined in more depth in Fabling and Grimes (2007), in which they found a link between "good" HRM practices (identified statistically as performance pay for most or all employees, and firmspecific (innovation-related) employee training) and firm profitability, productivity and market share.

Their most recent piece of work, Fabling and Grimes (2009), tested whether adoption of high performance human resource management (HRM) practices results in increases in labour and/or multi factor productivity within the firm.

This used a larger data set by adding matched firm data from the 2001 Firm Foundations and 2005 BOS, and performance data from Statistics New Zealand's Longitudinal Business Database (LBD).

The eight variables for HRM practices in the dataset were grouped into three "suites" according to statistical tests of co-prevalence.

They found that the General HRM suite (a general mix of individual practices) had a strong and statistically significant effect on MFP - improving practices by a factor of one would improve MFP by $11.5 \%$ economywide, and by greater amounts for all industries except Services. This improvement would require adoption of at least three HRM practices. 
The analysis also suggested that adoption of different HRM suites resulted in a statistically-significant association with higher growth in average wages, with some variation according to the suite of practices and the industries in which they were adopted.

UTS (2010) - the Management Matters global benchmarking project - collected data on measures of management performance from 152 medium and large manufacturing firms in New Zealand. It was intended to examine the link between management practices and performance at the firm level, and provide a comparison with manufacturing firms in 16 other (mostly developed) countries that were also analysed using this framework.

The link between practices and performance was demonstrated as a statistically significant relationship between management scores and profit per employee.

With regard to comparative performance of local firms and their offshore counterparts:

- New Zealand firms were ranked $10^{\text {th }}$ of 17 in overall management scores, placing this country in the middle tier of participants. Our firms were also in the middle tier for operations and performance management.

- $\quad$ however, they were in the bottom tier for people management, leading the authors to suggest that

... management of human capital through attracting, developing and retaining talent is the area that needs most attention from both corporate leaders and public policy.

The especially weak performance of New Zealand firms in managing their staff is arguably the most striking finding. Their performance is assessed as near the bottom of the rankings for

- $\quad$ addressing poor performers

- $\quad$ promoting high performers

- $\quad$ retaining high performers.

The notion of bundling improved management practices in a coherent, employment-centred package is often called High Performance Working (HPW). UKCES (2009) has an extensive summary of the relevant literature and empirical research (mostly from the UK).

This document defines HPW as

... a general approach to managing organisations that aims to stimulate more effective employee involvement and commitment to achieve high levels of performance

Citing UK research it suggests that

... there is now a substantial amount of evidence pointing to the positive association between $H P W$ and organisational performance and employee well-being at work. HPW, if it is implemented effectively, is linked with positive benefits in terms of a range of measures including improved company profits, sales and profitability, as well as wider improvements for employees, in terms of higher job satisfaction, better skill use and development, commitment and motivation.

The relevance of the HPW model became apparent to us in evaluating the impact of our productivity interventions, to which we now turn.

\section{Evaluation results}

\section{Background}

A number of 'action research' projects have been sponsored by the Department of Labour since 2006, the objectives of which included testing the effectiveness of business improvement strategies, and whether these resulted in higher levels of productivity within participating firms.

The approach taken was to fund business consultants to work with the firms, to identify and help implement practical steps to lift company performance.

In the following sections we discuss the firm-level findings of evaluations conducted by the Department in 2009 and 2010. These are complemented (and the findings reinforced) by studies of some of the individual projects (DoL/ITF 2008, EPMU/DWU 2010), detailed case studies of firms on the Department's website

(http://www.dol.govt.nz/workplaceproductivity/case-

studies/index.asp), and case studies of firms engaged in 'lean manufacturing' processes (DoL 2010a).

\section{Findings of the 2009 Evaluation}

The 'action research' projects (and a very similar one from another programme) were initially evaluated in 2009. The evaluations (DoL 2009a, 2009b) covered a number of matters such as implementation processes, delivery mechanisms and the like; of most relevance to this paper are the findings about what occurred within participating firms.

34 firms participated, with considerable variation in size and industry. 26 of the firms reported positive results from their involvement in terms of work culture and processes:

- increased worker involvement in improvements

- improved communication with management.

- increased knowledge and skills across the workplace, among both management and employees

- $\quad$ improved business planning

- improved work processes 
It appears that most firms are prepared to invest in improving workplace practices once they can see the benefits.

Managers of these 26 firms expressed confidence they were on the right path and, based on the benefits already experienced and anticipated for the future, were committed to continuous improvement.

In contrast the other eight firms made limited (if any) change to their internal culture and processes. The changes being introduced or proposed were not seen as contributing to improvement within the business.

The critical difference identified between the two types of firm was readiness. The 26 successful workplaces had

- relatively good internal communications, relationships and culture to start with

and

- managers who were ready, willing and able to make changes

While management of these firms generally lacked knowledge about what changes were needed and how to implement them, they recognised that they needed to do things differently, and were prepared to commit themselves and the firm to working through change processes.

The other eight workplaces all lacked this degree of readiness. Management was generally not ready and willing to make changes, and were unwilling to contribute the necessary resources to do so. The majority of these workplaces were also subject to strained employeremployee relationships.

DoL/ITF (2008) reached similar conclusions in respect of one project within the programme (covering seven firms) that was implemented in partnership with the Industry Training Federation.

iv ..., many small to medium sized employers are neither ready nor equipped (although they are willing!) to embrace these new qualifications [that would underpin smart manufacturing practices] or to begin significant change processes.

$v$ A considerable degree of 'pre-work' may be necessary to prepare companies to take advantage of new manufacturing technologies (e.g. Six Sigma). This is often due to the fact that change has to begin with company leadership and supervisory staff in such areas as how to conduct effective conversations with and engage their staff before specific improvement programmes can gain any traction.

\section{Findings of the 2010 Re-evaluation}

While the 2009 evaluation provided some useful findings and lessons, it was considered premature to fully draw conclusions about the significance and sustainability of the outcomes. Hence the Department conducted a reevaluation in mid-2010, interviewing 22 of the original firms (DoL 2010b).

Firstly, we explored the question as to whether better operational outcomes could be demonstrated and attributed to participation in the project. This approach was based on the above framework, as an alternative to attempting to directly measure productivity changes resulting from the projects.

The majority of participants identified a range of financial and performance benefits resulting to some degree from their participation in the project. Those gains had largely been sustained and, in many cases, increased over the previous year.

Many (but not all) firms were able to quantify improvements such as

- reductions in unit labour costs

- $\quad$ increased sales

- less waste and rework

- $\quad$ shorter lead times for new work

- better machine throughput

- more efficient and safer ways of working with machines.

(The latter both reduced accidents and ACC claims, and boosted production.)

Over half of the participants said that they achieved increases in profit in the 2009/10 financial year, which was at least partially attributed to the productivity improvement work. A number indicated that through the project they were able to maintain profit margins, or keep the reduction to manageable levels, and this was a better outcome than expected during the recession.

We also examined whether the improvements reported previously in workplace culture, communication and staff relations had continued after the support (funding of consultants) had ended.

Over half the companies interviewed confirmed continuing improvement, largely attributed to the processes generating their own momentum. Workplace culture had improved by a moderate to significant degree, by raising awareness of new approaches and facilitating a change in how managers and employees approached improvement.

Key outcomes included: 
- $\quad$ positive changes in leadership and management approaches

- noticeable improvements in morale

- a more open style of communication from company leaders

- greater staff involvement in operational decisions

- $\quad$ staff having pride in their work and a sense of being involved in the company

- working more closely with their customers, suppliers and competitors

- $\quad$ better customer service (which helped maintain or even gain customers during the recession).

However, sustaining this process proved challenging. In particular, in a number of the projects it was necessary to re-examine the role of the supervisor in a fundamental way, and to make changes to managers' communication and leadership styles.

Some participants reported that the involvement of unions in the projects helped open up communication between staff and management.

On the question of sustainability, we examined the extent to which productivity improvements had been maintained or even expanded in the year after the project officially ended.

The majority of companies reported that they continued with productivity improvement work after the end of the projects.

Participants reported that lifting workplace productivity was a relatively slow process but they felt that consistent small incremental changes could amount to significant improvements in the medium- to long-term.

Most participants used the momentum and culture shift created to further invest their own time and money in a wide range of other training and productivity programmes outside the scope of the initial projects. This commitment was based on the results seen to date and expected in the future. Noticeably, a number chose to keep the same consultants at their own expense.

Most companies noted the positive benefits of their project flowed into the marketplace, influencing their customers, suppliers and competitors.

There was general agreement among the participants that the productivity improvement projects were still a 'work in progress'.

\section{Conclusions}

\section{Implications of the evaluations}

How do we view the evaluation results in light of the other empirical analysis and the underlying framework?

Evaluations such as these are subject to a number of difficulties:

- establishing a counterfactual against which to measure outcomes - ie what would have occurred in these firms had they not been involved in the projects? In this case, this problem is particularly acute as the projects occurred during a recession, when firms were experiencing severe pressures on prices and sales/ production volumes.

- $\quad$ selection bias: are the firms 'representative' of the larger population of enterprises, or does their participation indicate that they were more likely to achieve positive results than non-participants? We consider that the former is highly likely.

- attribution: to what extent can positive outcomes be attributed to participation in the programme? A number of businesses were uncertain about the direct relationship between their participation and outcomes.

(See OECD 2007 for a summary of methodological issues in assessing the impacts of 'business assistance programmes'.)

Even recognising these difficulties, we consider that there are a number of conclusions and inferences that can reasonably be made from the above evaluations and the other studies referred to.

Firstly, there is a wide range of business improvement options that organisations can use, depending on their individual needs, and these can produce significant improvements in workplace practices.

Secondly, better workplace practices contribute to a range of better operational outcomes. These two findings are hardly surprising.

Eventually, benefits in productivity can be expected. These are harder to attribute, but we consider that they can be reasonably inferred in terms of our initial framework.

In our view, the most important finding from the evaluations is identifying reasons for differences in "success" - the conditions within firms that are necessary in order to improve the businesses, rather than the actual changes in workplace practices.

The experience of the organisations studied confirms the findings of the HPW literature in three critical aspects.

Firstly, they highlight the importance of employeecentred processes, which secure sustained commitment and active involvement from people at all levels of the organisation. 
Secondly, management needs to be committed to change, and the processes through which change is introduced - in other words, to be leaders not just administrators. And this applies to managers at all organisational levels.

Thirdly, the implementation process - ie the way in which changes are put in place - is at least as important as the actual changes made. Involvement of staff and positive leadership needs to be demonstrated and practiced consistently during these processes - 'walking the talk'.

There factors are graphically illustrated by the contrasting experiences of those organisations that had positive internal relationships and culture, and management leadership, and those where these conditions were absent. The first group could point to definite and sustained improvements; the second group achieved little.

\section{Directions for further research}

Studying the effects of workplace practices within firms is not novel - it has been the bread and butter of research in industrial relations, business studies and related disciplines for many years.

However, exploring the connections between workplace practices and productivity has not been done widely (from our review of the relevant literature). We see this as a highly productive stream of research (making no apologies for the pun). Micro-analysis at firm-level offers a way for researchers and policy makers to explore what goes on 'inside the black box', and could complement the top-down research about the impacts of regulation, market conditions etc.

This type of research is increasingly amenable to empirical analysis, using extensive data sets such as the BOS and the LBD. There is considerable scope for work spanning industrial relations, business studies and economics.

Moreover, many insights could come from disaggregating the data - testing for example, hypotheses about the types of work practices that appear to have most impact on productivity in different types of firm or different labour markets.

In particular, we would strongly urge researchers in this field to explore productivity impacts through the two-step process outlined above - from workplace practices to operational outcomes and thence to business performance. The framework outlined in this paper is relatively simple, and we believe useful insights could be found through a more disaggregated approach.

\section{References}

Department of Labour (DoL) (2009a). Workplace Productivity Projects - Evaluation Report, Strategic Research and Evaluation Unit, August 2009 http://www.dol.govt.nz/publications/research/wppevaluation-report/index.asp

Department of Labour (DoL) (2009b).AucklandPlus Productivity Project - Top Level Findings, Strategic Research and Evaluation Unit, November 2009

Department of Labour (DoL) (2010a). Lean Thinking and Productivity: Four Case Studies exploring the Anatomy of Lean Thinking in New Zealand Workplaces, Report prepared for the DoL by Owen Harvey, June 2010

http://www.dol.govt.nz/workplaceproductivity/lea $\underline{\text { n-thinking/lean-thinking.pdf }}$

Department of Labour (DoL) (2010b). Workplace Productivity Project Re-evaluation Report, Strategic Research and Evaluation Unit, October 2010 (forthcoming)

Department of Labour and Industry Training Federation (DoL/ITF) (2008). The SkillsProductivity Nexus: Connecting Industry Training and Business Performance, Report prepared for the DoL and ITF by Owen Harvey and Peter Harris, Innovation \& Systems Ltd, April 2008 http://dol.govt.nz/publications/research/publication -view.asp?ID=246

Engineering, Printing and Manufacturing Union and Dairy Workers Union (EPMU/DWU) (2010). High Performance work - Lifting productivity together, Project coordinators report, 8 February 2010

Fabling, R. and A. Grimes (2006). Practice Makes Profit: Business Practices and Firm Success, Ministry of Economic Development Occasional Paper 06/01, March 2006

http://www.med.govt.nz/templates/MultipageDoc umentTOC 22883.aspx

Fabling, R. and A. Grimes (2007). HR Practices and Firm Performance: What Matters and Who Does It? Ministry of Economic Development Occasional Paper 07/02, June 2007 http://www.med.govt.nz/upload/50973/07-02.pdf

Fabling, R., A. Grimes, L. Sanderson and P. Stevens (2008) Some rise by sin, and some by virtue fall: Firm dynamics, market structure and performance, Ministry of Economic Development Occasional Paper 08/01, May 2008

http://www.med.govt.nz/templates/MultipageDoc umentTOC 34197.aspx

Fabling, R. and A. Grimes (2009). The "suite" smell of success: Complementary personnel practices and firm performance, Reserve Bank of New Zealand Discussion Paper DP2009/13, December 2009 http://www.rbnz.govt.nz/research/discusspapers/dp 09 13.pdf

Ministry of Economic Development (MED) (2002). Firm Foundations - A Study of New Zealand 
Business Practices and Performance, December 2002

http://www.med.govt.nz/upload/5254/firm-

foundations.pdf

Organisation for Economic Growth and Development (OECD) (2004). Understanding Economic Growth A Macro-level, Industry-level, and Firm-level Perspective, Paris, 26 March 2004

http://www.oecdbookshop.org/oecd/getit.asp?REF=1104011E.PDF\&TYPE=browse

Organisation for Economic Growth and Development (OECD) (2007). OECD Framework for the Evaluation of SME and Entrepreneurship Policies and Programmes, Paris

Organisation for Economic Growth and Development (OECD) (2009). Structural Policies to Overcome Geographic Barriers and Create Prosperity in New Zealand, Economic Department Working Paper No. 696, ECO/WKP(2009)37, Paris, 28 April 2009 http://www.olis.oecd.org/olis/2009doc.nsf/LinkTo NT00002B4E/\$FILE/JT03263750.PDF

Statistics New Zealand (SNZ) (undated) Business Operations Survey

http://www.stats.govt.nz/methods and services/co mpleting-a-survey/business-surveys/busoperations-survey.aspx

Statistics New Zealand (SNZ) (2009). Business Operations Survey 2009, (questionnaire), $\mathrm{ED} / \mathrm{BOS} / 01$

http://www2.stats.govt.nz/domino/external/quest/s ddquest.nsf/12df43879eb9b25e4c256809001ee0fe/ a164150c09a0bdfbcc2576420019cdd3/\$FILE/ED BOS 01 09.pdf

Statistics New Zealand (SNZ) (2010). Productivity Statistics: 1978-2009, Hot off the Press, 16 March 2010

http://www.stats.govt.nz/browse for_stats/econom ic indicators/productivity/productivitystatistics ho tp7809.aspx

Treasury, The (2005). The Contributions from Firm Entry, Exit and Continuation to Labour Productivity Growth in New Zealand, New Zealand Treasury Productivity Paper TWP 05/01, March 2005

http://www.treasury.govt.nz/publications/research -policy/wp/2005/05-01/twp05-01.pdf

United Kingdom Commission for Employment and Skills (UKCES) (2009). High Performance Working: A Synthesis of Key Literature, Evidence Report 4, August 2009

http://www.ukces.org.uk/upload/pdf/UKCES\%20 Evidence\%20Report\%204.pdf

University of Technology, Sydney (UTS) (2010). Management Matters in New Zealand - how does manufacturing measure up? Findings from the New Zealand Management Practices and
Productivity global benchmarking project, Ministry of Economic Development, May 2010 http://www.med.govt.nz/templates/MultipageDocu mentTOC 43278.aspx 